\title{
TUTELA JURÍDICA DA PESSOA COM DEFICIÊNCIA: CONSIDERAÇÕES ACERCA DA CAPACIDADE PARA OS ATOS DA VIDA CIVIL
}

\section{THE LEGAL PROTECTION OF DISABLED PEOPLE: CONSIDERATIONS REGARDING THEIR CAPACITY FOR ACTS OF CIVIL LIFE}

\author{
Thaíse Mendes Ferreira ${ }^{1}$ \\ Karine Alves Gonçalves Mota ${ }^{2}$
}

\section{RESUMO}

O Estatuto da Pessoa com Deficiência (Lei no 13.146/15) implantou normas de inclusão dispostas anteriormente na Convenção Internacional sobre os Direitos da Pessoa com Deficiência, no entanto, as alterações promovidas na legislação civil geraram discussões no que tange a capacidade civil. Com isso essa pesquisa teve como objetivo geral apontar como o Estatuto da Pessoa com Deficiência visa garantir a tutela jurídica dos deficientes quanto à capacidade de exercício dos seus direitos. É uma pesquisa de caráter lógico-dedutivo, possuindo duas extensões para desenvolvimento, sendo explicativa e de caráter exploratório. A priori o trabalho fez um breve histórico dos direitos humanos, seguindo por um apanhado sobre os direitos das pessoas com deficiência e ademais construindo uma comparação entre a aplicação do instituto da capacidade civil anterior e posterior à nova redação dada ao Código Civil após a implantação da Lei no 13.146/15. Em concluso se discutirá os meios inseridos pela Lei Brasileira de Inclusão da Pessoa com Deficiência para assegurar a tutela jurídica dos deficientes em seu pleno exercício da capacidade civil.

Palavras-chave: Capacidade civil; Pessoa com deficiência; Tutela jurídica.

\footnotetext{
${ }_{1}^{1}$ Discente do curso de Direito da Faculdade Católica do Tocantins. E-mail: thaisemf@gmail.com

2 Doutora em Ciências pela Universidade de São Paulo. Mestre em Direito pela Universidade de Marília. Bacharel em Direito pela Pontifícia Universidade Católica de Goiás. Docente na Faculdade Católica do Tocantins.E-mail: karine.mota@catolica-to.edu.br
} 


\section{ABSTRACT}

The brazilian Statute of Desabled People (Law № 13.146/15), has implemented the inclusion previsions previously set forth in the International Convention on the Rights of People with Disabilities, however, the promoted alterations in civil law resulted in discussions regarding their civil capacity. That being said, this research had as its main objective pointing out how the Statute of Desabled people aims to guarantee legal protection of those individuals so they can exercise their rights. The research was of logical-deductive character and carried two development extensions, those being of explanatory and exploratory character. A priori, this survay offered a brief history of human rights, followed by an excerpt on the rights of disabled people and, finally, building a comparison between the application of the institute of civil capacity then and after the new wording given to the Civil Code due the implementation of the allusive Law.In conclusion, the means inserted by the Brazilian Law to ensure the legal protection of the disabled in the full exercise of their civil capacity will be discussed.

Keywords: Civil capacity. Disabled person. Legal protection.

\section{INTRODUÇÃO}

No dia 06 de Julho de 2019 completa 4 (quatro) anos da instituição da Lei Brasileira de Inclusão da Pessoa com Deficiência, autodenominada Estatuto da Pessoa com Deficiência, seu vigor começou em 03 de Janeiro de 2016 e trouxe modificações ao direito brasileiro. A essência desta lei está na Convenção Internacional sobre os Direitos da Pessoa com Deficiência que adentrou ao direito pátrio através do Decreto 6.949/2009.

A finalidade desta lei é reconhecer e amparar a autonomia e a capacidade legal a todos que possuem alguma deficiência, seja ela física, intelectual, mental ou sensorial, para isto as alterações tiveram como enfoque a modificação do sistema de incapacidades, iniciando as modificações pelos artigos $3^{\circ}$ e $4^{\circ}$ do Código Civil Brasileiro de 2002 que dispõe os tipos de incapacidades, diferenciando-as em relativa e absoluta.

A base dessa legislação é romper o preconceito entranhado na sociedade desde os tempos mais remotos que se tem conhecimento, para isso vem reafirmar que a pessoa com deficiência poderá assumir a plena capacidade civil da pessoa natural. 
Ao desassociar as deficiências da incapacidade questionou-se os reflexos que ocasionariam aos casos concretos, se de fato a lei cumpriria na aplicação o previsto na redação legal, conceder autonomia e concomitante proteger a pessoa plenamente capaz, mas que por alguma razão específica não possuísse discernimento suficiente para praticar todos os atos da vida civil. $\mathrm{Na}$ busca por uma resposta satisfatória aos questionamentos aplicou-se o método lógico-dedutivo, por meio da pesquisa explicativa/exploratória, fazendo uso do levantamento de dados bibliográficos e documental.

Destarte, o artigo será conduzido fazendo um breve apanhado histórico dos direitos humanos, da luta da pessoa com deficiência, em seguida comparando o antes e o depois do sistema da incapacidade provocado pela Lei de Inclusão, por fim apresentando as inovações promovidas e os reflexos ocasionados por elas, por se tratar de uma legislação relativamente recente ainda não há um entendimento unificado entre os doutrinadores e operadores do Direito.

\section{OS DIREITOS HUMANOS ENQUANTO FUNDAMENTO DA REPÚBLICA FEDERATIVA DO BRASIL}

\subsection{Pessoa com deficiência: participação, igualdade e autonomia}

A luta pelos direitos humanos não é acontecimento novo, desde o fim da Segunda Guerra Mundial em 1945, onde tivemos pode se dizer o maior massacre de direitos da história, e quando esta emergiu, foi criada a Organização das Nações Unidas com o objetivo de reacender a confiança nos direitos fundamentais, tais como dignidade e valor da pessoa humana. Este foi um dos passos mais importante para reafirmação dos direitos humanos, visto o grande abalo sofrido com as inúmeras ocorrências de total desrespeito durante a Segunda Guerra Mundial, no decorrer do tempo outros documentos também contribuíram para essa reafirmação até chegar à publicação da Declaração Universal dos Direitos Humanos.

Atualmente esses direitos encontram se positivados na Constituição da República Federativa do Brasil (CRFB), que dispõe em seus artigos princípios que 
resguardam a todo cidadão o mínimo para viver, todos estes princípios são importantíssimos, no entanto, a dignidade da pessoa humana é um preceito fundamental que está ligado aos direitos básicos e sociais do ser humano, tem sua previsão legal no artigo $1^{\circ}$, III da CRFB.

A submissão a este princípio fundamental reflete diretamente ao respeito e proteção à integridade física e moral garantindo que seja aceita a individualidade de cada pessoa, as pessoas com deficiência possuem esse princípio mais uma vez ratificado no artigo $8^{\circ}$ do Estatuto da Pessoa com Deficiência, essa necessidade de garantir, afirmar e ratificar em diversas legislações este princípio é resultado do triste passado que temos conhecimento através de relatos históricos do quão desumano eram as condições vividas pelas pessoas com deficiência.

Além das garantias elencadas na Carta Magna que podem ser encontradas nos artigos $5^{\circ} ; 7^{\circ}, \mathrm{XXXI} ; 23, \mathrm{II}, 24, \mathrm{XIV} ; 208$, III que buscam de diversas formas garantir e preservar alguns direitos da pessoa com deficiência, temos outras normas brasileiras que vale ressaltar que estão diretamente ligadas a garantia dos direitos básicos da pessoa com deficiência, são elas: Lei 10.098/2000 e Decreto 5.296/2004 que garante o direito de acessibilidade e Lei 10.048/2000 que normatiza o atendimento prioritário.

$O$ alcance dessa gama de direitos foi e continua a ser um grande desafio a todos, porém existem ainda aqueles que mesmo com tantas garantias adquiridas corriqueiramente encontram situações em que seu direito é atropelado, é o caso das pessoas com deficiência, pois não é suficiente ter esse princípio expresso em diversas legislações, é necessário que haja uma dedicação da sociedade para conscientização de todos, para que juntamente com os legisladores e judiciário criem políticas públicas capazes de viabilizar estes direitos a todo ser humano sem qualquer tipo de distinção.

A deficiência possui um histórico de carga negativa que a maioria das pessoas ainda hoje traz consigo, para o portador em alguns casos é tido como um fracasso pessoal, para os que vivem em torno é uma dificuldade a mais. A sociedade desde a antiguidade sempre ditou biótipos tidos como "normais" para a sociedade, e nesta "ditadura" nasce o preconceito que se enraíza e causa sofrimento a diversas pessoas, e com as pessoas com deficiência não é diferente. 
O Código Civil de 2002 elencava um rol que separava as pessoas com deficiência de alguns atos da vida civil, em 2006 a Assembleia Geral da Organização das Nações Unidas (ONU) homologou a convenção internacional sobre direitos das pessoas com deficiência, e posteriormente em 2015, foi promulgado o Estatuto, incidindo em alterações significativas no Código Civil.

\subsection{A incapacidade civil anterior e posterior ao estatuto da pessoa com deficiência}

Carlos Roberto Gonçalves (2018, p.111) define o instituto da incapacidade como: "é a restrição legal ao exercício dos atos da vida civil, imposta pela lei somente aos que, excepcionalmente, necessitam de proteção, pois a capacidade é a regra".

A legislação brasileira não se refere aos incapazes de direito, portanto a diferença está entre capacidade de fato ou de exercício. Assim, antes da vigência do Estatuto da Pessoa com Deficiência (Lei n. 13.146/2015), o Código Civil dividia a capacidade em dois tipos a absoluta e a relativa, tendo como base para a divisão o grau de imaturidade, deficiência mental. Destarte, o Código Civil (CC) elencava em seus artigos $3^{\circ}$ e $4^{\circ}$ os grupos aos quais pertencia cada pessoa conforme suas limitações, em vigor, a Lei então passa a tratar como absolutamente incapaz aquele que possui idade inferior a dezesseis anos, dentro dessas modificações, o grupo dos relativamente incapazes passa a ser composto por maiores de dezesseis e menores e dezoito anos; os ébrios habituais e os viciados em tóxicos; e aqueles que, por causa transitória ou permanente, não puderem exprimir suas vontades e os pródigos.

Diante desta classificação passava-se a preceituar em um capítulo específico sobre os meios de representação das pessoas relacionadas nos artigos $3^{\circ}$ e $4^{\circ}$ do CC, da mesma forma em que se dividiam as pessoas em dois grupos, também se fazia com os tipos de representação, sendo elas, legal e a voluntária, dispostas nos artigos 115 a 120 do CC.

A visão que se tinha dos referidos artigos que elencavam quem necessitaria de assistência, era que o legislador ao dispor de tais medidas, buscava a proteção aos incapazes. Gonçalves (2018, p. 132) menciona este entendimento em um subitem da 
sua obra, com palavras claras, expõe: "Código Civil contém um sistema de proteção aos incapazes. Em vários dispositivos constata-se a intenção do legislador em protegêlos, [...]".

O legislador deixava transparecer a preocupação tanto em proteger a pessoa portadora de necessidade especial, quanto os seus bens, tendo previsão de anulabilidade os negócios realizados em desconformidade com os requisitos da representação, da assistência e autorização judicial.

Ao expor o assunto de imputabilidade e responsabilidade o Código Civil no artigo 186, afirmando que para praticar ato ilícito e posterior ser obrigado a reparar o dano, este deverá possuir a capacidade de discernimento, aquele que não a possui não pratica ato ilícito. Os privados de discernimento (amental, louco ou demente), não serão responsáveis civilmente, atos por eles praticados equipara-se a caso fortuito ou força maior. Os casos em que o responsável pudesse ser imputado, esse responderia pelos atos e pelo dever de reparar, no entanto, nas situações que o mesmo não pudesse, o prejuízo ficaria para a vítima, não tendo a quem recorrer.

O Estatuto da Pessoa com Deficiência propiciou alterações quanto à responsabilização civil, em seu artigo $6^{\circ}$, caput proclama: "A deficiência não afeta a plena capacidade civil da pessoa", desta forma os privados de discernimento respondem diretamente por seus atos. Diante a premissa que a pessoa com deficiência tem capacidade legal e possui um conjunto de possibilidades de acordo com o artigo $6^{\circ}$ da Lei 13.146/15, como contrair casamento e união estável, assim por conseguinte, as alterações promovidas nos levam a concluir que, em regra, que estas pessoas são imputáveis, visto que para este o requisito é autonomia, assim serão responsabilizados pelos atos ilícitos que ocasionem danos atrelados a culpa.

Gonçalves faz uma ressalva quanto à consequência desta alteração, esclarecendo "a consequência direta e imediata dessa alteração legislativa é que o deficiente é agora considerado pessoa plenamente capaz. Desse modo, o amental, louco ou demente não mais respondem subsidiariamente por seus atos, mas sim diretamente" (GONÇALVES, 2018, p.113).

Existem posicionamentos diferentes relacionados às alterações proporcionadas pelo Estatuto, alguns acompanham a mesma linhagem de raciocínio de Gonçalves 
(2018), e outros como Costa (2017) entendem que as alterações implantadas são uma nova fase que proporcionará uma maior inclusão das pessoas com deficiência.

Araújo e Costa Filho (2016) de forma sintetizada cita as principais inovações dos institutos jurídicos que possuem relação direta com a deficiência, capacidade legal, acessibilidade e as avaliações psicossociais e ainda fazem ressalvas às alterações promovidas as normas nacionais, destacando como de maior intensidade as que ocorreram no Código Civil conforme o disposto nos artigos 114 a 116 do Estatuto, que fazem referência direta a teoria da incapacidade e ao instituto de interdição e curatela.

Ainda de acordo com os autores supratranscritos os impedimentos sejam eles físicos, sensoriais, mentais ou mesmo intelectuais não são capazes de restringir direitos, os maiores obstáculos para o exercício de qualquer direito encontra-se atrelados à cultura social.

São nítidas as alterações sofridas pelo sistema com a promulgação da Lei 13.146/15 denominada Estatuto da Pessoa com Deficiência ou abreviadamente tido como EPCD, vistas as alterações na parte principal do CC/02, o Estatuto modificou outros institutos que complementam e propiciam sentido específico as alterações mencionadas anteriormente.

Neste sentido Araújo e Costa Filho prelecionam:

Os artigos 114 a 116 da EPCD trouxeram modificações substanciais no Código Civil para fazer valer estes novos institutos da capacidade legal e da tomada de decisão apoiada e da nova concepção de curatela. Primeiramente retirou as pessoas com deficiência, inclusive as mentais e intelectuais, do rol dos absolutamente incapazes, remetendo-os para 0 rol dos relativamente incapazes, a partir de nova redação do art.4 combinado com as alterações

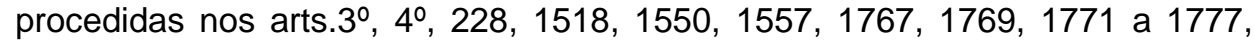
todos do Código Civil. Dessa forma as pessoas com deficiência, ordinariamente, só seriam interditadas em relação aos atos negociais e patrimoniais, mantendose as faculdades suas para casar, trabalhar, testemunhar, votar e praticar outros atos da vida diária. Tudo com eficácia imediata (ARAUJO; COSTA FILHO, 2016, p.22).

As críticas atreladas ao lado positivo da Lei № 13.146/15 afirmam que a forma como se aplicava o instituto da capacidade civil visava apenas a proteção de bens 
patrimoniais, e com isto ignorava direitos e garantias fundamentais previstos na Carta Magna. A autonomia existencial da pessoa com deficiência nos leva a uma unificação de tutela tanto patrimonial como existencial.

As alterações efetivadas pelo Estatuto objetiva a plena inclusão social, em prol da dignidade humana das pessoas com deficiência, tanto que, no contexto familiar o artigo $6^{\circ}$ concomitante com o artigo 84 do referido estatuto concede o pleno direito de exercício para que estas pessoas constituam seus lares com igualdade de oportunidades concedidas as demais pessoas, para casar, ter filhos, seja reproduzindo ou adotando.

A nova teoria das incapacidades é um instrumento de afirmação que defende a não retirada da capacidade legal das pessoas com deficiência para gerir atos da vida civil, baseado apenas no ser diferente, a Lei de Inclusão propicia a busca pelo reconhecimento do direito à singularidade.

Além das alterações apresentadas, o Estatuto da Pessoa com Deficiência incluiu um novo instituto ao ordenamento jurídico, a "Tomada de Decisão Apoiada", disposto na Lei 13.146/15 no capítulo II - DO RECONHECIMENTO IGUAL PERANTE A LEI, artigo 84, $\S 2^{\circ}$, acrescido ao Código Civil como artigo 1.783-A, disposto em 11 (onze) parágrafos $(\S)$ como se dará tal instrumento.

\section{A EXCEPCIONALIDADE DOS INSTRUMENTOS DE PROTEÇÃO INTRODUZIDA PELA LEI 13.146/15}

De acordo com os resultados do Censo Demográfico em 2010 (IBGE) mais de 45 milhões de pessoas apresentavam algum tipo de deficiência, o que correspondia a cerca de $23,9 \%$ do total da população. Os números apresentados já demonstravam a necessidade dos órgãos responsáveis investir em políticas específicas para esse grupo.

Em 06 de Julho de 2015 foi publicada a lei 13.146 - Estatuto da Pessoa com Deficiência (também chamada de Lei Brasileira de Inclusão da Pessoa com Deficiência), diploma que carrega em sua essência, direitos levantados anteriormente pela Convenção sobre os Direitos da Pessoa com Deficiência, tratado internacional que foi ratificado pelo Brasil com força de norma constitucional. 
O primeiro artigo da novel legislação dispõe sobre seu intuito, dissertando que está destinada a assegurar e promover condições de igualdade, exercício de direitos e garantias de liberdades fundamentais à pessoa com deficiência, tendo como preliminar sua inclusão social e cidadania. No segundo artigo a lei define quem são pessoas com deficiência, as que estarão tuteladas nos demais dispositivos, sendo elas, aquela que possui algum impedimento a longo prazo de natureza física, mental, intelectual ou sensorial que a impeça de participar de forma plena, efetiva e igual com as demais pessoas na sociedade.

A Lei 13.146/15 suscitou alterações no que tange a capacidade civil ao trazer em seu artigo $6^{\circ}$ que a deficiência não afeta a capacidade civil plena da pessoa, Requião (2016) defende que as mudanças não implicam na possibilidade de um portador de transtorno mental ter sua capacidade limitada para certos atos, o que afasta é a condição de incapaz, podendo ser submetido à ação de interdição. No intuito de dirimir os questionamentos acerca da proteção destes que poderiam ter capacidade civil limitada, o Estatuto trouxe o instituto da "Tomada de Decisão Apoiada".

Esse mecanismo adotado alterou o Título IV do Livro IV da Parte Especial do Código Civil, passando a ser intitulado como: "Da Tutela, Da Curatela e Da Tomada de Decisão Apoiada", como mencionada no item anterior a tomada de decisão apoiada vem disposta no capítulo III que em seu artigo 1.783-A dispõe:

Art. 1.783-A. A tomada de decisão apoiada é o processo pelo qual a pessoa com deficiência elege pelo menos 2 (duas) pessoas idôneas, com as quais mantenha vínculos e que gozem de sua confiança, para prestar-Ihe apoio na tomada de decisão sobre atos da vida civil, fornecendo-lhes os elementos e informações necessários para que possa exercer sua capacidade (BRASIL, 2018).

Gaburri (2016) faz questão de frisar em sua obra que o mecanismo de tomada de decisão apoiada não se confunde com os outros institutos como a tutela e a curatela, aquele versa sobre a proteção a direitos patrimoniais de pessoa capaz que, no entanto apresenta alguma deficiência, enquanto estes são medidas direcionadas a pessoa incapaz, seja na tutela para menores de dezesseis anos ou na curatela, para maiores, que não conseguem exprimirem suas vontades. 
Com esse mesmo entendimento Gonçalves (2018) exemplifica em que este instrumento poderá ser utilizado em consonância ao entendimento da Lei, para ele, poderá ser aplicada a tomada de decisão aos casos em que a pessoa possui alguma deficiência, no entanto, tal não impede que a pessoa seja capaz de exprimir a sua vontade, neste caso cita como o exemplo as pessoas com Síndrome de Down.

Desta forma como se veem esclarecendo nos tópicos anteriores passamos a entender como o Estatuto da Pessoa com Deficiência visa garantir a tutela jurídica dos deficientes, a tomada de decisão apoiada é tida como o mecanismo essencial para assegurar a capacidade do exercício de direitos, bem como também é aplicada para resguardar os vulneráveis em situações negociais.

No que concerne ao caráter aplicado da tomada de decisão apoiada, Gaburri (2016) alega que se trata de um negócio jurídico gratuito, plurilateral, solene, personalíssimo, que pode ter ou não prazo definido, onde prevalece o interesse da pessoa com deficiência que no momento da sua decisão estará apoiada por duas ou mais pessoas de sua escolha para garantir a preservação do seu interesse.

De acordo com a Lei 13.146/15 o processo para tomada de decisão apoiada é autônomo e possui rito próprio e participam dele, além da parte interessada e das duas pessoas apoiadoras indicadas por ela, o juiz, que será assistido por uma equipe multidisciplinar e o Ministério Público.

Para requerer a tomada de decisão apoiada à pessoa com deficiência apresenta ao juiz petição escrita por meio de defensores públicos ou advogados, suscitando que o juiz nomeie os apoiadores por ela indicado. Após a nomeação determinada pelo juiz, os apoiadores passarão a auxiliar os atos da vida civil, esclarecendo duvidas e fornecendo as informações necessárias para que a pessoa com deficiência tenha seus interesses e/ ou direitos respeitados.

A decisão tomada por pessoa apoiada possui validade e gera efeitos sobre terceiros sem que aja qualquer restrição, caso o negócio jurídico vier a demonstrar riscos ou mesmo prejuízo, ou na ocorrência de divergência entre pessoa com deficiência e apoiadores, o juiz após ouvir o Ministério Público (M.P) decidirá a lide. A qualquer tempo poderá ser solicitada a tomada de decisão apoiada, também a qualquer 
instante poderá a pessoa deficiente solicitar o término do acordo assinado ou mesmo a exclusão do processo de nomeação dos apoiadores.

O instituto da Curatela não se trata de uma inovação trazida pelo Estatuto, no entanto, sofreu algumas alterações que merecem destaque ao abordar os meios adotados para garantir o amparo legal dos deficientes.

A curatela é processo judicial onde o juiz atua assistido por uma equipe multiprofissional analisando a capacidade civil de uma pessoa com 18 (dezoito) anos ou mais para o exercício de seus direitos, ao final do processo o juiz decide se a mesma está apta ou não a praticar atos de caráter patrimonial, ou se necessitará de auxílio, tal ação de curatela pode ser pleiteada por pais, tutores, cônjuge ou qualquer parente, pelo interessado e até mesmo pelo M.P, como dispõe a Seção I do Capítulo II do Código Civil Brasileiro.

O artigo 1.167 do CC/02 foi reestruturado para trazer a nova redação dada pelo Estatuto quanto à natureza da deficiência, sendo sujeito à curatela aqueles que por causa transitória ou permanente, não possam exprimir a sua vontade, os ébrios habituais e os viciados em tóxicos e os pródigos.

O processo da ação de curatela é instaurado após manifestação através de um advogado ou defensor de um interessado legítimo, o juiz analisa o pedido e chama a pessoa com deficiência para uma audiência de entrevista onde é solicitada que fala sobre sua vida, negócios, e outros aspectos. Com o auxílio da equipe o juiz determinará se é cabível e quais os limites da curatela. Ao final do processo o juiz determinará o menor prazo possível e designara data para revisão da aplicação do instituto.

Com o advento destes dois mecanismos desencadeou entre os doutrinadores questionamentos quanto à extinção da ação de interdição, visto que o Estatuto da Pessoa com Deficiência não faz menção ao termo, em contrapartida o Código de Processo Civil publicado em 13 de Março de 2015, anterior ao Estatuto ainda faz menção das palavras "interdição" e "interditando" em seu artigo 747.

Araujo e Costa Filho esclarecem que uma interpretação sistemática pode solucionar as contradições e que a aplicação das regras do direito são essenciais nestas circunstâncias, vejamos: 
Numa análise mais específica, vejo que o CPC não previu a obrigatoriedade de equipe multiprofissional e a avaliação biopsicossocial do interditando, criando uma faculdade ao juiz para determinar a avaliação por equipe multidisciplinar (termo usado no CPC), bastando um laudo para caracterizar a incapacidade. Isto poderia criar um aparente conflito entre essas duas normas e por tabela com o Código Civil reformado pelas duas. Para dirimir conflitos das leis temos três critérios definidos no art.2 ${ }^{\circ}$ da Lei de Introdução ao Código Civil (LICC): 1) Hierárquico: quando entre duas normas, prevalece a superior; 2) Cronológico: quando entre duas normas, prevalece a mais recente; e 3) Especial: quando entre duas normas, prevalece a especial sobre a geral. Diante desse critério verificaríamos que no conflito entre CPC e EPCD prevaleceria a EPCD por ser especializada às pessoas com deficiência, as quais precisam ser protegidas $\mathrm{e}$ pela sua vulnerabilidade por força constitucional (Art. 23 e $24 \mathrm{CF}$ ). E ainda é importante observar que a EPCD é norma de direito material que prevalece sobre a de direito processual em regra geral (ARAUJO; COSTA FILHO, 2016, p.27).

Ao que concerne o uso do termo interdição tem sim a ideia de incapacidade, no entanto, ao se aplicar o que se refere na norma de prevalência, a especial, o objetivo fim é alcançado.

A modificação da capacidade civil não alterou apenas os artigos $3^{\circ}$ e $4^{\circ}$ do $\mathrm{CC}$, influenciou também em alterações aos institutos da prescrição e da decadência, que anteriormente não corria contra os deficientes, com a Lei 13.146/15 passou a contar prazos prescricionais a todos os deficientes que não são tidos como incapazes com previsão na nova redação do artigo $3^{\circ}$ do CC, como dispõe o artigo 198, I, do CC, assim somente não correrá a prescrição para os menores de 16 anos, que são tidos como absolutamente incapazes após a implantação do Estatuto.

Neste contexto, Daneluzzi e Mathias (2016) posicionam-se afirmando que essa alteração causará prejuízos patrimoniais, causando a desproteção tida anteriormente ao Estatuto nestes atos negociais, posicionando a favor da proteção a pessoa com deficiência, expressando:

Melhor seria que se mantivesse a proteção legislativa da pessoa com deficiência, pois em que pese a capacidade, as condições pessoais podem exigir amparo jurídico, considerando o real prejuízo em decorrência do transcurso do prazo prescricional em seu desfavor (DANELUZZI; MATHIAS, 2016, p.6). 
Ao analisar de forma minuciosa este contexto, verificamos que neste ponto o legislador, pode sim ter ocasionado uma posição desfavorável, prejudicando os vulneráveis. Neste caso, remetemos ao pensamento aristotélico que "devemos tratar igualmente os iguais e desigualmente os desiguais, na medida de sua desigualdade" (DANELUZZI; MATHIAS, 2016, p.6). Diante disto, afirmamos que sempre caberá para aplicação do Direito de forma menos desigual a possibilidade de alterar os institutos.

Diferentemente do regime anterior, onde o negócio jurídico praticado por uma pessoa com deficiência sem a devida representação, era nulo e a ação que atestasse tal nulidade poderia ser impetrada a qualquer tempo, o regime proposto pela Lei Brasileira de Inclusão modificou este instrumento de salvaguarda, com a instituição de plenamente capaz, corre contra a pessoa com deficiência o prazo de usucapião contra si, prazo de prescrição em seu desfavor. A responsabilidade civil era tida como subsidiária, ou seja, aquela em que respondia com seu próprio patrimônio pelo dano causado, caso o que the representasse não houvesse condições de arcar.

Houveram modificações também quanto ao instituto da decadência, de acordo com o artigo 178, III do CC aplica-se o prazo de 4 (quatro) anos para pleitear a anulação de um negócio jurídico praticado sem a representação adequada, contados do momento que cessar a incapacidade, no entanto, dependerá do enquadramento da pessoa como incapaz, ficando a mercê da interpretação dada ao caso concreto. Se acolhida a interpretação normativa de que a pessoa com deficiência não pode ser tratada como incapaz, eliminaremos qualquer medida protetiva, sendo assim plausível afirmar que a responsabilidade será rígida e direta propiciando a aplicação da reparação total dos danos causados e aceitação do prejuízo ocasionado pelo negócio praticado.

Barros (2018) critica o legislador, pois de acordo com ele essas alterações supracitadas que alteraram o regime de dignidade-vulnerabilidade para dignidadeautonomia necessitaria de maiores reflexões para a implantação ser eficaz na sua totalidade, pois no que concerne aos negócios com terceiros a pessoa com deficiência poderá achar-se em desvantagem. Em curtas palavras afirma "representa grave violação do princípio da isonomia substancial, pelo qual os desiguais devem ser 
tratados de forma desigual na exata proporção da desigualdade" (BARROS, 2018, p. 201).

Seguindo este entendimento e tendo como válido podemos afirmar que as medidas acima implantadas violam redação da Convenção Internacional sobre os Direitos das Pessoas com Deficiência, intitulado como Decreto 6.949/2009, em seu artigo 12, item 4 , dispõe que toda medida relativa ao exercício da capacidade legal deve conter instrumentos de salvaguardas que sejam apropriados e efetivos, tais mecanismos visam a prevenção de abusos e a prevalência dos direitos e vontades da pessoa.

Ao comparar este Estatuto com o Código de Defesa do Consumidor no que diz respeito a isonomia substancial, vemos que o Código legisla com mecanismos que buscam proteger o consumidor considerando este como vulnerável ou mesmo hipossuficiente nas relações de consumo, neste exemplo entendemos a possível falha cometida pelo legislador ao promover a Lei em estudo sem destacar de forma clara os mecanismos que seriam aplicáveis aos casos emblemáticos, que hoje dependem da interpretação do aplicador.

\section{REFLEXOS DO ESTATUTO DA PESSOA COM DEFICIÊNCIA NO NEGÓCIO JURÍDICO}

O estudo dos negócios jurídicos doutrinariamente é feito através de uma tripartição criada por Pontes de Miranda conhecida como "Escada Ponteana" que consiste em três planos: de existência, validade e eficácia. A existência é composta pela vontade, as partes e o objeto; a validade se consolida com a capacidade das partes, a licitude negociável do objeto e a forma; por fim a eficácia, é a capacidade do negócio jurídico gerar efeitos, ou seja, contém as condições resolutivas ou suspensivas, na legislação brasileira a previsão deste está disposta no artigo 104 do Código Civil (MIRANDA apud SILVA, 2017).

Diante das inovações proporcionadas pelo Estatuto ressalta-se que qualquer pessoa com deficiência poderá realizar sozinha negócios jurídicos, não estando esta 
submetida aos institutos da curatela ou decisão apoiada ainda sim poderá executar todos os atos da vida civil, visto que é plenamente capaz.

No campo da discussão das alterações ocasionadas pela Lei de Inclusão, levante-se a ideia da criação de um entrave no que concerne a vitalidade do negócio jurídico praticado pela pessoa com deficiência, pois de acordo com o entendimento do Promotor de Justiça Cristiano Chaves Faria (2016) o Estatuto é omisso não diferenciando o tipo e o grau de deficiência a ser arrolada no artigo $4^{\circ}$ do código civilista, e isso leva a entender que até mesmo uma pessoa com deficiência mental grave é apenas relativamente incapaz.

Em contrapartida e de forma diversa expressa os autores Loureiro, Martinez e Martins Junior (2018), para eles o ponto crítico desta discussão é a falta de compreensão dos efeitos por parte da pessoa com doença mental grave no ato da sua declaração de vontade, assim ocasionando o efeito de anulabilidade dos atos (previsão artigo 171, CC). Pondera-se que a intenção destas pessoas existe, no entanto, suas ações podem surtir efeitos desagradáveis, causando-lhe até mesmo prejuízos patrimoniais.

Correlacionado a esse argumento surge a figura da curatela, contudo, levanta-se a hipótese de não ser tão eficaz, visto que, o curador poderá se beneficiar desta condição.

Salienta-se que o negócio jurídico pode ser anulado (artigo 171, CC) desde que seja arguido pela parte interessada e respeitando o prazo decadencial de quatro anos previstos no código civilista artigos 177 e 178, respectivamente.

Apesar de não haver diferenciação quanto ao grau ou tipo de incapacidade, com a alteração do Código Civil, alguns julgados utilizam-se de outros mecanismos para a aplicação da incapacidade absoluta, apossando-se de critérios para análise do caso concreto, vistas ao laudo pericial e a possibilidade do julgamento através da declaração incidental de inconstitucionalidade de uma referida legislação, neste sentido, examinemos os julgados, trazendo pontos e contrapontos dos fundamentos diferentes utilizados: 
EMENTA: APELAÇÃO. DIREITO DE FAMÍLIA. AÇÃO DE INTERDIÇÃO. INTERDITANDO PORTADOR DE DEMÊNCIA. DECLARAÇÃO INCIDENTAL DE INCONSTITUCIONALIDADE DOS ARTIGOS 84, "CAPUT", e $\S 3^{\circ}$, 85, "CAPUT", $\S$ 10 e $\S 20$, AMBOS DA LEI 13.146/2015. INCONSTITUCIONALIDADE NÃO VERIFICADA PELO FATO DE HAVER REGRAS ABERTAS. INCAPACIDADE ATESTADA POR LAUDO PERICIAL. EXERCÍCIO DA CURATELA PARA TODOS OS ATOS DA VIDA CIVIL. PECULIARIDADES DO CASO CONCRETO. POSSIBILIDADE. RECURSO PARCIALMENTE PROVIDO. - A Lei no 13.146/2015, que instituiu o Estatuto da Pessoa com Deficiência, não viola os artigos $3^{\circ}$ e $5^{\circ}$ da Constituição Federal, estando de acordo com o previsto no Decreto no 6.949/2009, que promulgou a Convenção Internacional sobre os Direitos das Pessoas com Deficiência e seu Protocolo Facultativo, assinados em Nova York, em 30 de março de 2007, e que detém "status" equivalente ao de emenda constitucional, na forma do art. $5^{\circ}$, $\S 3^{\circ}$, da Constituição Federal - É verdade que a Lei usa termos amplos, abertos, postos à interpretação, e que podem ser entendidos --- como certa parte da doutrina o faz - como "zonas cinzentas" que contrariam o direito. Assim não ocorre, porém. O fato da indeterminação, da possibilidade de interpretar, da fluidez dos conceitos, da abertura das vontades, da indefinição, nada disso é contra a lei. Nada disso desfigura a Constituição. O convívio com a diferença se faz com regras diferentes. Regras rígidas, regras que não admitem interpretação, regras pétreas, não possuem lugar hoje no terreno mais amplo das liberdades do deficiente, principalmente o deficiente mental, cujo universo é, na verdade, desconhecido pela ciência em seu atual estágio. A convivência com todo este complexo esquema de normas e regras é a melhor solução e a Constituição o abriga - Por sua vez, os casos de sujeição à curatela, previstos no art. 1.767 do CC, foram restringidos, sendo delimitado pelo art. 85 da Lei no $13.146 / 2015$ que "a curatela afetará tão somente os atos relacionados aos direitos de natureza patrimonial e negocial". Busca-se preservar um nicho de liberdade, um canto de independência e de autonomia ao curatelado naquilo que a sua incapacidade de vontade própria não chega a atingir, uma fresta de liberdade que a ciência moderna identifica e que o Direito buscou tutelar e proteger, o que se faz sem qualquer vício de inconstitucionalidade - Em se tratando de ação de interdição, cuja natureza especial visa resguardar a proteção da dignidade da pessoa que se reputa incapaz, faz-se necessária prova concreta acerca da incapacidade civil - Conforme decidido pelo Órgão Especial deste Tribunal, no julgamento da Arguição de Inconstitucionalidade no 1.0000.17.034419-6/002, "Ao estabelecer que a 'curatela afetará tão somente os atos relacionados aos direitos de natureza patrimonial e negocial', o art. 85, § $1^{\circ}$, da Lei $\mathrm{n}^{\circ}$ 13.146/15, não estipulou que o exercício do direito se daria de maneira absoluta, já que ressalvada a proporcionalidade da definição da curatela às necessidades e circunstâncias de cada caso." - No caso, o estabelecimento da curatela para todos os atos da vida civil mostra-se adequado à situação de extrema incapacidade vivenciada pelo interditado, devendo, portanto, ser mantida a r. sentença no tocante à extensão dos efeitos da curatela para além das questões patrimoniais e negociais (TJ-MG - AC: 10024141653824001 MG, Relator: Wander Marotta, Data de Julgamento: 05/02/2019, Data de Publicação: 12/02/2019).

O julgado apresentado acima decidiu por incapacidade absoluta para todos os atos da vida civil, visto que diante do laudo pericial concluso e o testemunho da perita 
do caso atestou-se que o interditando tinha capacidade de expressar, pois ainda falava mesmo com dificuldades, todavia, isso não foi o suficiente para mantê-lo apenas como relativamente capaz, a incapacidade acometida dificultava as atividades básicas do cotidiano como a higiene pessoal. Esta foi defendida afirmando que não era 0 afastamento de um diploma legal, mas sim a aplicação em sua forma mais pura de proteção.

Além da decisão do Tribunal de Justiça de Minas Gerais, o Supremo Tribunal Justiça também possui julgados após a promulgação do Estatuto da Pessoa com Deficiência que decidiu por aplicar a ação de interdição, vejamos:

AGRAVO EM RECURSO ESPECIAL № 1.091.069 - RS (2017/0093338-1) RELATOR : MINISTRO RICARDO VILLAS BÔAS CUEVA AGRAVANTE : O R DA R ADVOGADO : DEFENSORIA PÚBLICA DO ESTADO DO RIO GRANDE DO SUL AGRAVADO : D C R DA R ADVOGADO : GILBERTO MACHADO HAAS - RS087780 INTERES. : J V R DA R DECISÃO Trata-se de agravo interposto por $O \mathrm{R}$ DA $\mathrm{R}$ contra decisão que inadmitiu recurso especial. $\mathrm{O}$ apelo extremo, fundamentado no artigo 105, inciso III, alínea a, da Constituição Federal, insurge-se contra acórdão do Tribunal de Justiça do Estado do Rio Grande do Sul, assim ementado: "AÇÃO DE INTERDIÇÃO. INCAPACIDADE CIVIL. Comprovada pela prova pericial a incapacidade da interditanda de reger sua pessoa e administrar os seus bens, pelo comprometimento das suas faculdades mentais, justifica-se a interdição, que é instituto de caráter eminentemente protetivo. Recurso desprovido" (e-STJ fl. 402). No recurso especial, a recorrente alega violação do art. 1.772 do Código Civil, ao fundamento de que a interdição deve ser decretada apenas de forma parcial, em relação a questões que envolvam administração de bens de elevado valor, pois o transtorno de humor afetivo e/ou bipolar que lhe acomete não a torna pessoa absolutamente incapaz para exercer todos os atos da vida civil. Aduz que frequenta curso superior em universidade federal, ou seja, a redução do discernimento não impede a prática de atos da vida cotidiana. Aduz que os laudos médicos acostados não são conclusivos em relação à sua total incapacidade, podendo seus sintomas ser controlados com o uso de medicamentos. Sem as contrarrazões, foi negado seguimento ao recurso especial, dando ensejo à interposição do presente agravo. O Ministério Público Federal opinou pelo não provimento do recurso. É o relatório. DECIDO. Ultrapassados os requisitos de admissibilidade do agravo, passa-se ao exame do recurso especial. A insurgência não merece prosperar. Cuida-se de ação de interdição proposta contra a recorrente por seu filho, julgada procedente em primeiro grau. A sentença foi mantida pelo Tribunal estadual, haja vista que ficou comprovado por meio de prova pericial a incapacidade total da recorrente, conforme se extrai da leitura do voto condutor, merecendo destaque o seguinte trecho: (...) Com efeito, observo que trata-se de ação de interdição e que restou cabalmente comprovado pela prova pericial a absoluta incapacidade de OTIBIA D. R. de reger sua pessoa, administrar os seus bens e praticar atos da vida civil, em razão do comprometimento das suas faculdades mentais, justificando-se plenamente a interdição, que é instituto de 
caráter eminentemente protetivo da pessoa. O laudo médico de fls. 84/85 foi conclusivo no sentido de que 'A examinada apresenta Transtorno Esquizoafetivo do tipo maníaco, codificado F25.0 na Classificação Internacional de Doenças em sua $10^{\mathrm{a}}$ edição (CID 10). Assim sendo, é totalmente e definitivamente incapaz para os atos da vida civil'. No mesmo sentido, a última avaliação médica realizada (fl. 244), datada de 04 de abril de 2015, na qual restou consignado que 'A mesma no presente momento não apresenta condições para discernimento, necessitando de pessoa idônea para cuidar de seus interesses'. Dessa forma, restou cabalmente comprovada a incapacidade total de OTIBIA para o exercício dos atos da vida civil, sendo totalmente descabida, no caso, a interdição parcial pleiteada (e-STJ fls. 404/405). Nesse contexto, denota-se que o acolhimento da pretensão recursal demandaria o revolvimento do acervo fático-probatório dos autos, o que se mostra inviável ante a natureza excepcional da via eleita, a teor do enunciado da Súmula no 7 deste Superior Tribunal. Ante o exposto, conheço do agravo para não conhecer do recurso especial. Publique-se. Intimem-se. Brasília (DF), 09 de junho de 2017. Ministro RICARDO VILLAS BÔAS CUEVA Relator (STJ - AREsp: 1091069 RS 2017/0093338-1, Relator: Ministro RICARDO VILLAS BÔAS CUEVA, Data de Publicação: DJ 26/06/2017)

Se observado minuciosamente o Estatuto da Pessoa com Deficiência poderemos verificar que há lacunas que dependem da interpretação do aplicador da lei e que pode incorrer em conflitos com previsões de artigos do mesmo estatuto, é o que vemos com os dois julgados que decidiram por acatar o instituto da interdição, visto que a Lei Brasileira de Inclusão não faz referência a aplicação deste, pois com a alteração promovida não há mais que se falar em incapacidade absoluta.

Neste contexto Barros (2018, p. 202) se posiciona de forma categórica:

Diante da omissão legislativa quanto à criação de medidas de proteção da vontade manifestada por deficientes, torna-se difícil criticar a postura de diversos juízes que continuam decretando a interdição de pessoas com doença/deficiência mental grave e declarando a incapacidade absoluta para prática de atos patrimoniais, afastando parcialmente a incidência do Estatuto da Pessoa com Deficiência.

Em partes a aplicação da interdição está diretamente ligada com a falta de adequação do Código de Processo Civil que traz em suas previsões legais a nomenclatura da interdição, no entanto, é incompatível com a visão proposta pela Lei Brasileira de Inclusão, a mesma propôs uma filosofia inteiramente de inserção das pessoas com deficiência a sociedade como um todo. 
Como já citado em outros momentos os novos institutos sejam eles implantados ou os modificados como é o caso da curatela, são apoiadores para aqueles que necessitam de assistência, mas esta não se aplica a valores constitucionais como a liberdade e a intimidade, o Estatuto afirma que a mesma deverá ser restrita apenas as necessidades especificadas de cada caso e á no menor tempo possível. Para a Lei 13.146/15 a curatela somente seria aplicável aos atos que litigassem sobre direitos de ordem patrimonial/negocial e ainda sim o interesse fundamental do curatelado deve ser respeitado.

Contudo, espera-se que diante de lacunas da lei os operadores do direito supram-nas e elucidem conflitos mediante uma interpretação da Lei Brasileira de Inclusão da Pessoa com Deficiência, autodenominada Estatuto da Pessoa com Deficiência - Lei 13.146/15, tendo como concepção o prisma civil-constitucional, que independentemente do texto legal, a prioridade dada seja a garantir a proteção da pessoa com deficiência atendendo os anseios de defender em qualquer caso pela prevalência da dignidade humana, respeitando a lei maior, a Constituição Federal, mesmo que para isso tenha que relativizar a autonomia no campo do direito civil.

\section{CONSIDERAÇÕES FINAIS}

Com a Lei Brasileira de Inclusão (13.146/15) houve consideráveis modificações no que tange a capacidade civil disposta no código civilista, as alterações não ficaram somente no âmbito civil refletiu em outras normas do Direito, tais como: consumidor, penal, trânsito e outros, no entanto, este estudo empreendeu em discutir sobre os reflexos desta novel legislação no que concerne à capacidade para os atos da vida civil, validade dos negócios geridos por pessoa com deficiência, trazendo inicialmente um contexto histórico de como o direito e as particularidades destes foram alcançadas por essa parcela da sociedade que merece total respeito e atenção.

É notório que a legislação possui a essência de garantir autonomia a pessoa com deficiência, seja ela mental, intelectual, física ou sensorial, propiciando a elas que constituam famílias, tenham a quantidade de filhos que desejarem, dentre outras garantias, mas em contrapartida, algumas lacunas ocasionaram questionamentos ao 
operador do Direito, ressalta-se aos efeitos nos negócios jurídicos entende-se que está alteração reduziu a proteção dos deficientes quanto ao ato de invalidação.

Mais inovações foram trazidas pelo Estatuto da Pessoa com Deficiência, a curatela ganhou alterações significativas, tendo caráter secundário e se sobressaindo, em regra, para atos patrimoniais. A tomada de decisão é uma inovação que propícia um maior aproveitamento da autonomia.

No entanto, dentre as alterações notou-se a ausência de instituto que resguardasse a pessoa com deficiência mental grave, nestes casos fica a cargo do operador do Direito buscar auxílios em outros meios, atendendo sempre a essência da norma em garantir a proteção dos maiores interessados, as pessoas com deficiência.

\section{REFERÊNCIAS}

ARAUJO, Luiz Alberto David; COSTA FILHO, Waldir Macieira da. A lei 13.146/2015 (o estatuto da pessoa com deficiência ou a lei brasileira de inclusão da pessoa com deficiência) e sua efetividade. Direito e Desenvolvimento, João Pessoa, v. 7, n. 13, p. 12-30, jun. 2016. Disponível em:< https://doaj.org/article/5e44999f840d4db99835f2c89fd4d41c>. Acesso em: 17 nov. 2018.

BARROS, André Borges de Carvalho. Os efeitos do Estatuto da Pessoa com Deficiência no sistema brasileiro de incapacidade civil. Revista dos Tribunais Online, v. 988/2018, p. 195-214, fev.2018. Disponível em:<https://www.revistadostribunais.com.br/maf/app/resultList/document?\&src=rl\&srgui $\mathrm{d}=\mathrm{i} 0 \mathrm{ad} 82 \mathrm{~d} 9 \mathrm{~b} 00000169 \mathrm{f} 98 \mathrm{~b} 49 \mathrm{~d} 619460466 \&$ docguid=I609da880fd9c11e7a9e201000000 $0000 \&$ hitguid $=1609 \mathrm{da} 880 \mathrm{fd} 9 \mathrm{c} 11 \mathrm{e} 7 \mathrm{a} 9 \mathrm{e} 2010000000000 \&$ spos $=1 \& \mathrm{epos}=1 \& \mathrm{td}=1 \& \mathrm{context}=$ $16 \&$ crumb-action=append\&crumblabel=Documento\&isDocFG=false\&isFromMultiSumm=\&startChunk=1\&endChunk=1 > . Acesso em: 03 mar. 2019.

BRASIL. Código civil brasileiro e legislação correlata. - 2. ed. - Brasília: Senado Federal, Subsecretaria de Edições Técnicas, 2008. 143 p. Disponível em: <https://www2.senado.leg.br/bdsf/bitstream/handle/id/70327/C\%C3\%B3digo\%20Civil\%2 02\%20ed.pdf>. Acesso em: 05 out. 2018.

. Constituição da República Federativa do Brasil. Brasília: Senado Federal, 1988.Mesa diretora - biênio 2015/2016.

. Decreto no 6.949, de 25 de agosto de 2009. Promulga a Convenção Internacional sobre os Direitos das Pessoas com Deficiência e seu Protocolo 
Facultativo, assinados em Nova York, em 30 de março de 2007. In: Planalto, Brasília. Disponível em: <http://www.planalto.gov.br/ccivil_03/_ato20072010/2009/decreto/d6949.htm>. Acesso em: 07 abr. 2019.

. IBGE. Censo Demográfico: 2010: características gerais da população, religião e pessoas com deficiência. Rio de Janeiro, 2010. Disponível em:< https://biblioteca.ibge.gov.br/pt/biblioteca-catalogo?view=detalhes\&id=794>. Acesso em: 24 nov. 2018.

Lei oㅜ 13146, de 06 de julho de 2015. Institui a Lei Brasileira de Inclusão da Pessoa com Deficiência (Estatuto da Pessoa com Deficiência). In: Diário Oficial da República Federativa do Brasil, Brasília, DF, 07 jul. 2015. Disponível em: <http://www.planalto.gov.br/ccivil_03/_ato2015-2018/2015/lei/l13146.htm>. Acesso em: 02 out. 2018.

. Supremo Tribunal de Justiça - STJ. Agravo em recurso especial no 1.091.069 - RS. Relator: Ministro Ricardo Villas Bôas Cueva. DJ: 26/06/2017. JusBrasil, 2019. Disponível em:<https://stj.jusbrasil.com.br/jurisprudencia/472358451/agravo-emrecurso-especial-aresp-1091069-rs-2017-0093338-1?ref=juris-tabs>. Acesso em: 07 abr. 2019.

. Tribunal de Justiça de Minas Gerais TJ-MG. Apelação Cível no AC 10024141653824001. Relator: Wander Marotta. DJ: 05/05/2019. JusBrasil, 2019. Disponível em: <https://tj-mg.jusbrasil.com.br/jurisprudencia/674539440/apelacao-civelac-10024141653824001-mg/inteiro-teor-674539566? ref=serp>. Acesso em: 24 mar. 2019.

COSTA. Klecyus Weyne de Oliveira. A lei brasileira de inclusão da pessoa com deficiência e o regime das incapacidades no código civil. Cadernos do Ministério Público do Estado do Ceará: Escola Superior do Ministério Público do Ceará ESMP, Fortaleza, v. 1, n. 1, ISSN 2526-8740b p.173-212, jan. 2017. Disponível em: $<$ http://www.mpce.mp.br/institucional/esmp/biblioteca/revista-eletronica/cadernos-doministerio-publico-do-estado-do-ceara/cadernos-do-ministerio-publico-do-estado-doceara-edicao-atual/cadernos-do-ministerio-publico-do-estado-do-ceara-ano-i-no-i-vol-12017/>. Acesso em: 05 out. 2018.

DANELUZZI, Maria Helena Marques Braceiro; MATHIAS, Maria Ligia Coelho.

Repercussão do estatuto da pessoa com deficiência (lei 13.146/2015), nas legislações civil e processual civil. Revista dos Tribunais Online, Curitiba, v. 66/2016, n. 1, p.118, abr. 2016. Disponível em:

<http://www.civel.mppr.mp.br/arquivos/File/Artigo_Repercussao_EPD_Legislacoes_Civil _Processual_Maria_Helena_Marques.pdf>. Acesso em: 16 nov. 2018.

FARIAS, Cristiano Chaves de. Estatuto da Pessoa com Deficiência Comentado artigo por artigo I Cristiano Chaves de Farias, Rogério Sanches Cunha, Ronaldo Batista Pinto. 2. rev., ampl. e atual. - Salvador: Ed. JusPodivm, 2016. 416p. Disponível 
em:< https://forumdeconcursos.com/wp-content/uploads/wpforo/attachments/2/1541Estatuto-da-Pessoa-com-Deficincia-comentada.pdf>. Acesso em: 24 mar. 2019.

GABURRI, Fernando. Capacidade e tomada de decisão apoiada: implicações do estatuto da pessoa com deficiência no direito civil. Direito e Desenvolvimento, João Pessoa, v. 7, n. 13, p. 118-135, jun. 2016. Disponível em:< https://doaj.org/article/01b5d045f9e54af78cf5e96ec5f8c8d0>. Acesso em: 23 de nov. 2018.

GONÇALVES, Carlos Roberto. Direito civil brasileiro, v.4: responsabilidade civil - 13 . ed. - São Paulo: Saraiva Educação, 2018.

GONÇALVES, Carlos Roberto. Direito civil brasileiro, v.1: parte geral - 16. ed. - São Paulo: Saraiva Educação, 2018.

LOUREIRO, Nayara dos Santos; MARTINEZ, Adilsen Claudia; MARTINS JUNIOR, Antonio Carlos. Deficiente mental: os negócios jurídicos por ele celebrados. Revista Diálogos Interdisciplinares, Mogi das Cruzes, v. 4, n. 1, p.79-101, 11 jun. 2018. Disponível em: <https://revistas.brazcubas.br/index.php/dialogos/article/view/352>. Acesso em: 20 mar. 2019.

SILVA, Lucas Guedes Pereira da. A aplicabilidade do estatuto do idoso aos efeitos dos contratos de plano privado de assistência à saúde anteriores à sua vigência: um exame acerca da legalidade da incidência de reajustes contratuais nos preços das mensalidades nos planos de saúde em razão de mudança de faixa etária aos consumidores idosos. 2017. 94 f. Tese (Doutorado) - Curso de Direito, Universidade Federal do Rio Grande do Norte, Natal, 2017. Disponível em: <https://monografias.ufrn.br/jspui/bitstream/123456789/5647/1/LucasGPS_Monografia.p df>. Acesso em: 07 abr. 2019. 